\title{
Efficient and Effective Public Spending for Sustainable Economic Growth
}

\author{
Ph. D. Candidate Asel Azhykulova (International Ataturk Alatoo University, Kyrgyzstan)
}

\begin{abstract}
Nowadays, governments are more careful with the use of resources and attempt to be efficient and effective to achieve sustainable economic development. This paper contrasts the efficiency and effectiveness of public spending of developed and developing countries in current conditions and their impact on economic growth.

The author analyses efficiency and effectiveness measures of public spending applied by prominent crosscountry empirical studies. The critical success factors for the effective performance of government through World Bank indicator of government effectiveness highlights the role of effective public budget policy. In addition, the Public Sector Performance Index and Public Sector Efficiency Index introduced by Vito Tanzi and other measures of Livio di Matteo, Konstantinos Angelopoulos are examined. Based on these approaches the author proposes several suggestions for the current condition of public budget policies of Central Asian countries and ways of improving the effectiveness and efficiency levels of their public sector.

The author argues that the assumption that developing countries are less efficient than developed countries are based on several efficiency variations: the size of government expenditure, a government budget composition, aid dependency, and weak institutions. What is more, findings suggest that countries with relatively small governments that use resources more efficiently tend to achieve higher levels of economic growth that is not always the case for all developed countries. These findings have important implications for assessing the government performance on economic growth.
\end{abstract}

\section{Introduction}

Today governments play a different role than before. Starting with the classic theory of Adam Smith's limited intervention, and Keynes anti-crisis instruments of substantial intervention, and Buchanan's theory of public choice of reasonable intervention government's role changed. Nowadays, governments are more careful with the use of resources and attempt to be efficient and effective to achieve sustainable economic development. They pay more attention to performance measurement and evaluation in the public sector because of several developments over recent decades. The financial crisis of 2008-2009, debt crisis, and a tremendous fall of GDP, all has shown that governments are not effective. What's more, it has shown that problems of governance is actual for not only developing and transition countries, but for the highly developed parts of the world (Rothstein, 2011). The international organizations, such as IMF, World Bank, OECD, etc. with governments are for the sound public finance that allows for sustainable and effective budget policy in especially the time of globalization when borders are widely open and opportunity for economic growth is restrained by tough competition and pressure on government's revenue base.

The rest of the paper is as follows. Section 2 explains the concept of public sector performance. Section 3 analyses efficiency measures of prominent empirical cross-country studies. Section 4 analyses the efficiency variations and proposes suggestions for Central Asian countries. Section 5 concludes.

\section{Public Sector Performance}

It is often believed that countries with more effective governments tend to have economy that is more effective. Many empirical researches suggest that, it is true, and that countries with more effective government tend to achieve higher levels of economic growth by obtaining better credit ratings and attracting more investment, offering higher quality public services and encouraging higher levels of human capital accumulation, putting foreign aid resources to better use, accelerating technological innovation, and increasing the productivity of government spending (Rajkumar and Swaroop, 2002). Old scholars strongly believed that effective government can boost economic growth. Old exogenous Neo-classical growth theory (Solow, 1956) and new endogenous growth theory (e.g. Lucas, 1988). Jan S. Hogendorn (Hogendorn, 1996) highlights significance of an efficient government in group of six important factors of economic development: "An economic system that allows for efficient allocation, including increases in the efficiency of government". Marc Holzer (Holzer, 1992) proposes "productive government", highlighting the role of fiscal policy: "... no government can remain fiscally sound if it is inefficient and ineffective". Also he suggests for public agencies to improve their capacities to be productive, to apply those capacities to the efficient and effective delivery of services, and to convince the public that such actions are occurring. The author suggests measuring productivity through efficiency, effectiveness, impact, and performance, particularly by total quality management tools. Prominent study of Vito Tanzi also suggests the significant role of government in economic growth, suggesting more efficient use of public resources (Tanzi, 2005). More recent research is drawing attention to enhance the government effectiveness 
through sound public finance management. Research done by World Bank suggests that economic development can be achieved through implementing the principles of sound public finance. According to approaches in "Public Finance for Sustainable Development" research, there are three main goals of public expenditure management systems: fiscal discipline, allocative efficiency and cost-effectiveness.

Fiscal discipline - implementing constraints on the aggregate level of spending and deficits over the medium term;

Allocative efficiency - prioritizing competing claims of different social objectives on scarce resources in the best possible way using cost-benefit analysis and incidence analysis tools.

Cost-effectiveness is defined simply as that "public finance schemes should achieve their goals at a minimum costs".

What's more, as Rothstein, Allen Schick also highlights the fact that sustainable public budget policy is just a problem of developing countries but a core issue of developed countries, mainly because of aging population of OECD countries causing surge in public spending on pension and healthcare. He suggests four dimensions of sustainable public budget policy (Schick, 2005):

- Solvency - the ability of government to pay its financial obligations.

- Growth - fiscal policy that sustains economic growth.

- Stability - the capacity of government to meet future obligations with existing tax burdens.

- Fairness - the capacity of government to pay current obligations without shifting the cost to future generations.

Here we should pay attention to new important pillar of the economic development that compels to consider equity dimensions in attempts to grow sustainably. Starting with Joseph Stiglitz there is a tradeoff between efficiency and equity dimensions. Moreover, recent studies strongly highlights the role of fair distribution of national wealth among people in the way of growing.

Thus, sustainable growth is possible with balanced budget with expenditures that brings efficiency and effectiveness and fair allocation of the achievements of economic development. This study will concentrate on the ways how efficiency and effectiveness dimensions are measured and what policy implications can be suggested for Central Asian countries.

We have to start with identifying when government is effective. How we define "effective government"? Certainly, there is no common definition. It is a subset of the relatively new concept of "good governance" (Roshtein and Teorell, 2012). World Bank Governance Indicator (WGI) suggests it is one of the six composite indicators: Voice and Accountability, Political Stability, Government Effectiveness, Control of Corruption, Rule of Law, and Regulatory Quality. It utilizes 37 measures from 15 sources: "Government effectiveness captures perceptions of the quality of public services, the quality of the civil service and the degree of its independence from political pressures, the quality of policy formulation and implementation, and the credibility of the government's commitment to such policies" (Worldwide Governance Indicators, 2013). Certainly, this is qualitybased indicator, widespread and comprehensive cross-country analysis.

Another way of determining the government effectiveness is through evaluating efficiency and effectiveness of public sector performance. As clarified by Worthington and Dollery (Worthington and Dollery, 2000), efficiency and effectiveness is two different parts of performance.

$$
\begin{array}{ll}
\text { Efficiency } & \text { Performance } \\
\text { Resource Management } & \text { Outcomes Accessibility } \\
\text { Quality Appropriateness }
\end{array}
$$

In conceptual framework of efficiency and effectiveness (Ulrike Mandl et al., 2008) the relationship of inputs, outputs and outcomes is analyzed. The input-output ratio is measurement of efficiency, outcome is effectiveness. Input-output relates to outcome, meaning by efficiency we can achieve effectiveness. For example education spending as input gives educated people as output and it will affect economic growth as an outcome. Thus, as more efficient or productive public spending is used, the better result is achieved, enhanced economic growth in particular.

Thus, the public sector performance of any government can be evaluated through analyzing its public budget policy, efficiency and effectiveness of public spending particularly. Today many states define the public sector performance as the use of the least resources in achieving maximum results.

In IMF publications two conditions mentioned for public expenditure programs to be efficient or "productive": lowest possible cost (cost-effective) and appropriate mix of outputs and sustainable levels of aggregate expenditure (the mix of public sector outputs should be optimal and consistent with a sustainable 
macroeconomic framework). "In the simple case of one public good, the optimum provision of that good is achieved when the marginal social benefit derived from the good is equal to the marginal social cost of providing it" (Chu et al., 1995).

Important step to take is getting rid of first of all unnecessary spending. According to Baumol (Baumol and Bradford, 1970), government spending should be used more efficiently than in the private sector, as they were originally removed from the scope of certain inefficient private sector. So, only spending in those areas where government is really efficient. "This can be achieved by reducing unproductive expenditures while shifting budgetary resources toward areas that support the development of essential physical infrastructure and human capital, including basic health and primary education. Barro (Barro, 1990) study distinguishes between productive and non-productive government spending categories and between distortionary and non-distortionary taxes.

The methods of measuring efficiency is represented by contemporary econometric analysis methods, such as parametric and non-parametric methods. Various cross-country studies are built on these methods and they do not give certain results. They are rather contradictory.

In this study, we will analyse the Central Asian countries' public sector performance based on the approaches used by the comprehensive cross-country comparison of four important studies of World Bank, Livio di Matteo, and Vito Tanzi et al. and Konstantinos Angelopoulos et al. to compare public sector performance of countries of Central Asia. To find a good comprehensive data for Central Asian countries, namely Armenia, Azerbaijan, Georgia, Kazakhstan, Kyrgyz Republic, Tajikistan, Turkmenistan, and Uzbekistan is a difficult task. The author spent a lot of time researching World Development Indicator, IMF World Economic Outlook, ADB database, Global Competitiveness Index, IRIS-3 dataset, etc., unfortunately, it is impossible at least for now. This is a main cause of almost no empirical study for Central Asian countries on this most significant subject in recent conditions. This study marks the beginning of a new empirical study and will contribute to enhancement of the public sector performance and its impact on sustainable growth of Central Asian countries.

\section{Efficiency Measures of Prominent Empirical Studies}

\subsection{Worldwide Governance Indicator (WGI)}

The WGI project, a research dataset produced by Daniel Kaufmann, Aart Kraay, Massimo Mastruzzi reports aggregate and individual governance indicators for 215 economies over the period 1996-2013.

Important conclusions:

1. Improving governance indicators help fight poverty and improve living standards.

2. Good governance is not an exclusive prerogative of the rich countries.

3. Where there is commitment to reform, improvements in governance can and do occur.

4. Significant improvements in governance can and do happen.

5. However, in general, there is no evidence of a significant improvement in the quality of governance in the world over the past decade.

6. Assessment of governance is difficult enough, and all management measures are absolutely accurate, requiring careful interpretation.

Government effectiveness of 212 countries are compared in a study that range from -2.5 to +2.5 . The lowest line is occupied by countries of Africa, North Korea, and Afghanistan. Close to the middle of the chart are Central Asian countries Turkmenistan (-1.3) Tajikistan (-1.1), Uzbekistan (-0.9), Kyrgyzstan (-0.7), Kazakhstan $(-0,5)$, and Russia (- 0.4), India (-0.2), Brazil (-0.1). Right in the middle are China (0), Armenia (0.1), Saudi Arabia (0.1), Thailand (0.2), Mexico (0.3), Greece (0.4), Turkey (0.4), Georgia (0.5), Italy (0.5). And leaders are EU countries, the Asian tigers, Japan, USA, Canada. The first three are Finland, Singapore and Denmark.

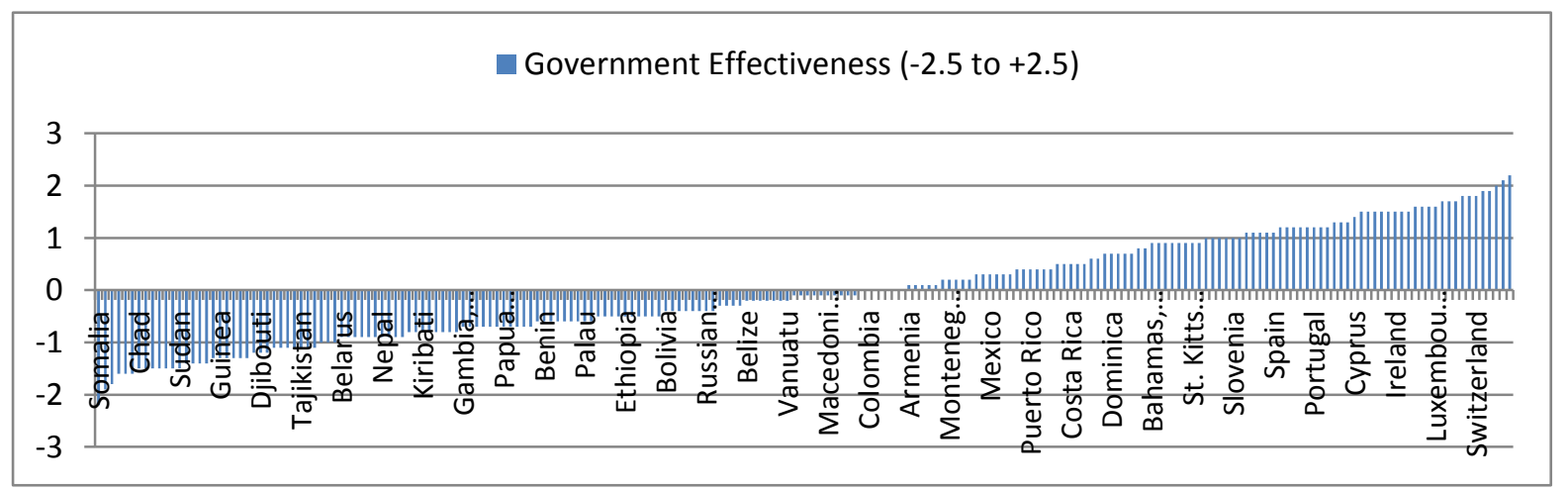

Figure 1 Government Effectiveness scores across countries, WDI. 


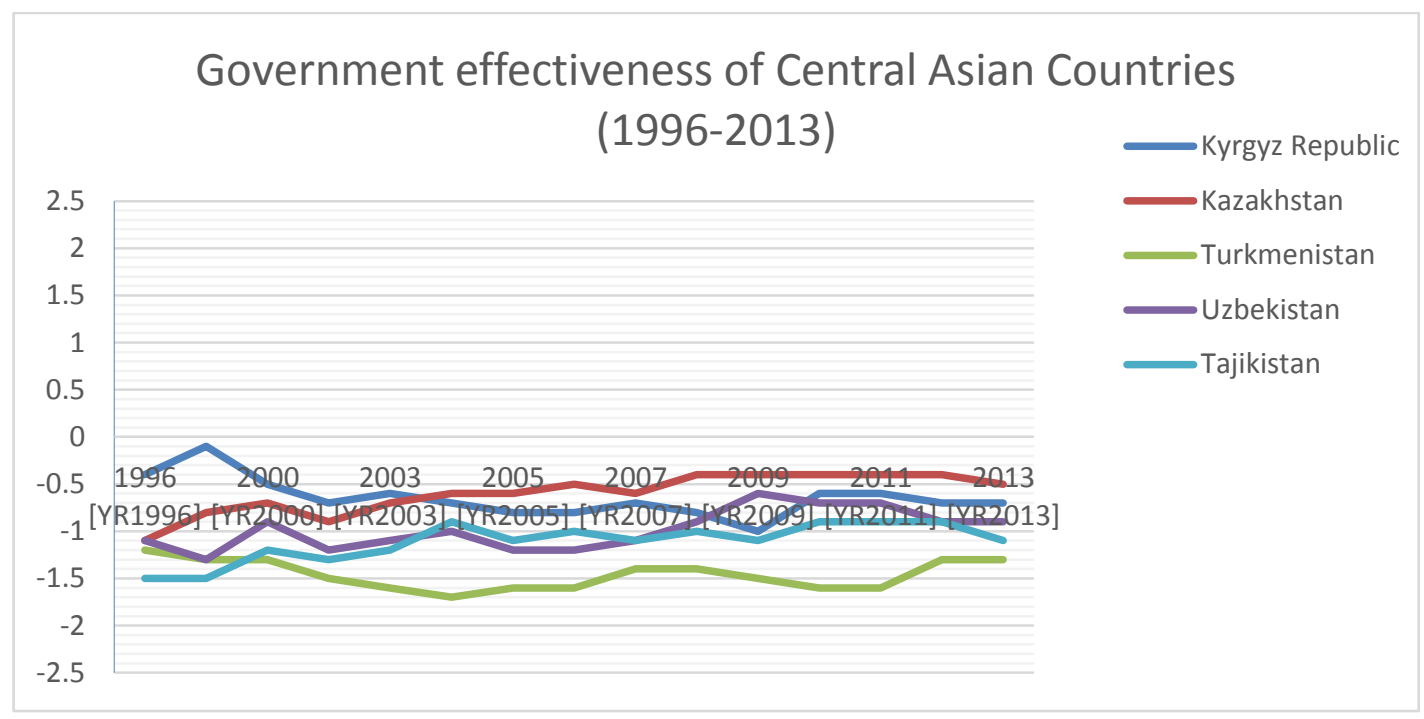

Figure 2. Government Effectiveness score for Central Asian countries, WDI.

Central Asian countries Kazakhstan, Uzbekistan, Tajikistan, Kyrgyzstan, and Turkmenistan government effectiveness levels are lying near to each other. Kazakhstan improved its level and is the best performing among others, followed by Kyrgyz Republic, whose level decreased and now second in list. Uzbekistan is the third and a slight up and downs. Tajikistan level is improving, but decreased to the fourth place. Turkmenistan started good but gradually fall to last place in the list.

\subsection{Livio di Matteo}

The second cross-country study of 34 OECD countries for years of 2000-2011 by Livio di Matteo presents an index of efficiency. An international overview of the size and efficiency of public spending named "Measuring government in 21st century" by Livio di Matteo (Matteo, 2013a) analyzed the role of government in influencing economic growth and specifically study on examining the theories relating the size of the public sector and economic growth. This index is computed by using OECD data by combining a set of outcome indicators with government size data. 20 indicators are chosen: 4 economic performance indicators (inflation, unemployment rate, level of per capita GDP, real per capita GDP growth rate); 2 health outcome performance indicators (life expectancy, infant mortality); 5 social outcome performance indicators (tertiary education, PISA reading score proportion, Gini coefficient, homicide rate, burglary rate); and 9 better life indicators (rooms per person, household net adjusted disposable income, household net financial wealth, life satisfaction, self-reported health status, voter turnout, air pollution, water quality).

Total performance index score and government expenditure to GDP ratio clearly shows the most efficient public sector is currently that of South Korea followed by Luxembourg, Switzerland, Australia, and Norway: "They illustrate that the goal is not a smaller public sector per se, but a smaller public sector given a performance level". In order to understand this conclusion we should compare the highest cost-effective countries (South Korea, Luxembourg, and Switzerland) with the least cost-effective countries (Greece, Hungary and Turkey). Luxembourg's performance index (7.5) is higher than Korea's (5.8). But the government expenditure to GDP ratio of Luxembourg is 40.5 percent, and Korea's 27.4, which means that Luxembourg has a public sector of $48 \%$ larger than Korea, but performing for only 29 percent better than Korea. Turkey as the least cost-effective country has a public sector of 36 percent and performance index score is only 2.5. Hungary and Greece public sectors are close to 50 percent while performance index is just 4 .

The important conclusion the authors made is that the relationship between the government expenditure to GDP ratio and the growth rate of per capita GDP has a hump-shaped Scully curve. "All other things given, annual per capita GDP growth is maximized at 3.1 percent at a government expenditure to GDP ratio of 26 percent; beyond this ratio, economic growth rates decline. This demonstrates that there is an optimal size for the public sector when it comes solely to the effect on economic growth. Naturally, what size the public sector should be is also about broader societal outcomes but, even then, the evidence suggests that there are few additional benefits once the public sector reaches 30 to 35 percent of GDP" (Matteo, 2013b).

\subsection{Vito Tanzi et al.}

Prominent scholars, Vito Tanzi et al. particularly explores the changing role of the government and highlights the importance of government effectiveness through enhancing public spending effectiveness and efficiency (Tanzi, 2011). Vito Tanzi suggests, “Achieving multiple objectives of stabilization, growth and equity requires not only reducing expenditures, where necessary, but improving the efficiency and composition of public expenditures" (Tanzi, 1997). "A fundamental role of the state would be to make markets work well by becoming 
more efficient and more transparent. This, in fact, should be seen as the most fundamental role of the state in a market economy. The government should be ruthless in the pursuit of that objective" (Tanzi, 2005). In addition, the author defines the effective government such as, when the focus of public expenditure is on agreed activities (genuine public goods, significant externalities, the creation of social institutions and the rule of law that protect individuals and property) suggested by Adam Smith, Pigou, Musgrave, Samuelson and others, than it is carried out in an efficient manner, the public sector remains small and efficient.

Recent research of Vito Tanzi et al., on "Public sector efficiency: evidence for new EU member states and emerging markets" core question is "... whether there is a positive, identifiable relationship between higher public spending and higher social welfare" (Tanzi et al., 2010). Two indicators, the Public Sector Performance (PSP) index and the Public Sector Efficiency (PSE) index are used for comparative analysis. Seven indicators of public sector performance are used in the calculation of the index and are broadly classified into two groups: opportunity indicators (administrative performance, education performance, health performance, public infrastructure outcomes) and Musgravian indicators (income distribution, economic stabilization, resource allocation). Opportunity indicators can show government's performance in promoting equal opportunities and Musgravian indicators can show how government is performing three main functions of public finance.

\begin{tabular}{lcccc} 
& Rank & PSE score & PSP score & $\begin{array}{c}\text { Government expenditure } \\
\text { to GDP ratio }\end{array}$ \\
\hline Singapore & 1 & 2.39 & 1.53 & 21.0 \\
Thailand & 2 & 1.83 & 1.07 & 17.8 \\
Korea & 3 & 1.65 & 1.14 & 24.4 \\
Mauritius & 4 & 1.56 & 1.05 & 24.7 \\
Chile & 5 & 1.38 & 0.94 & 24.4 \\
Ireland & 6 & 1.37 & 1.24 & 33.0 \\
Mexico & 7 & 1.31 & 0.84 & 25.3 \\
Cyprus & 8 & 1.08 & 1.33 & 40.0 \\
Greece & 9 & 0.96 & 1.09 & 48.6 \\
South Africa & 10 & 0.95 & 0.81 & 26.3 \\
Slovak Republic & 11 & 0.92 & 1.03 & 43.8 \\
Latvia & 12 & 0.91 & 0.95 & 36.6 \\
Estonia & 12 & 0.91 & 0.97 & 36.4 \\
Slovenia & 14 & 0.88 & 1.12 & 42.1 \\
Romania & 15 & 0.86 & 0.78 & 33.7 \\
Lithuania & 16 & 0.86 & 0.90 & 33.3 \\
Czech Republic & 17 & 0.85 & 0.97 & 40.6 \\
Hungary & 17 & 0.85 & 1.05 & 50.2 \\
Poland & 19 & 0.83 & 0.96 & 43.2 \\
Portugal & 20 & 0.83 & 1.04 & 46.2 \\
Malta & 21 & 0.78 & 1.15 & 45.0 \\
Bulgaria & 22 & 0.77 & 0.74 & 38.6 \\
Brazil & 23 & 0.69 & 0.75 & 46.6 \\
Turkey & 24 & 0.63 & 0.74 & 42.7 \\
\hline
\end{tabular}

Table 1. Ranked PSE and PSP scores and government expenditure to GDP rations.

The authors concluded that: "The results of our analysis show that expenditure efficiency across new EU member states is rather diverse especially compared to the group of top performing emerging markets in Asia. From the analysis of composite PSP and PSE scores, we find that countries with lean public sectors and public expenditure ratios not far from $30 \%$ of GDP tend to be most efficient. PSE scores of the most efficient countries are more than twice as high as those of the poorest performers".

\subsection{Konstantinos Angelopoulos et al.}

A rather different cross-country study exists that of Konstantinos Angelopoulos et al. (Angelopoulos et al. 2008) which was built on Vito Tanzi et al. study. This study compares the performance of governments in 64 developed and developing countries for 1980-2000 years. It differs from other studies in that it examines the relationship between fiscal size and economic growth that explicitly depends on the efficiency of the public sector. In order to find Public Sector Efficiency (PSE) index, they used a measure of Public Sector Performance index (PSP) and a measure of Public Sector Expenditure (PEX) index based on the assumption that particular activity expenditure is allocated to achieve this particular performance. They constructed PSE not on 7 indicators as Vito Tanzi et al., but four indicators of Education, Administration, Infrastructure, and Stabilization due to limited data for 64 countries. In the policy area of education they measure the Secondary School Enrollment and Public Spending in Education; In the policy area of administration they measure Corruption in Government and Bureaucratic Quality; In the policy area of infrastructure they measure Diesel Locomotives in Use and Electric 
Power Transmission and Distribution Losses; In the policy area of stabilization, the PSP is measured by the average of the inverse of the variables Inflation Rate and Unemployment Rate.

It is basically the ratio of performance indicators to associated expenditures: PSE = PSP / PEX

The authors concluded: "The policy implication is that what matters to growth is not the size per se, but the size-efficiency mix. Of course, improving the efficiency of the public sector is not an easy task. It requires, among other things, the reallocation of government resources, as well as the effective and efficient use of those resources towards identified and transparent strategic priorities".

\subsection{Other Studies}

Most comprehensive empirical research has been done by Slemrod in 1995, a cross-country study that "evaluates the evidence about the influence of government tax and expenditures on economic prosperity and growth" (Slemrod, 1995). The author attempted to analyze this impact by assessing two sides of government intervention. First, was to assess the different services of government: provision of public goods, maintenance of full employment, insurance against social risks, income maintenance, and adequate provision of certain basic goods and services. Second, was to assess the cost, in terms of a lower average standard of living, of the programs designed to achieve this goal. He used two approaches to measuring these costs: bottom-up and topdown approaches. As a result of this study authors concluded: "This review of the existing cross-country literature suggests that there is no persuasive evidence that the extent of government has either a positive or a negative impact on either the level or the growth rate of per capita income, largely because the fundamental problems of identification have not yet been adequately addressed".

Another comprehensive study of Nijkamp, P. and J. Poot (2004), in a meta-analysis of 41 studies, the author found that only 17 percent of studies show positive relationship between different measures of fiscal policy and economic growth; 29 percent showed negative relationships; and 54 percent were inconclusive. There is no certain evidence of government revenue and expenditures impact on long-term growth and suggesting that majority of study finds the growth enhancing impact of specific government expenditures like education and infrastructure.

Handler et al. (2005) suggested more efficiency to smaller, rather than larger, government.

By analyzing much of the prominent research work Lee and Whithford "... find that much of the variation in effectiveness is explained by the relative position of countries in the worldwide income distribution, with wealthier countries experience greater perceptions of effectiveness and those in the lower parts of the distribution being perceived as being less effective" (Lee and Whithford, 2009).

\section{Why Contradictory Results?}

One explanation to all above-mentioned contradictions gives Bergh and Henrekson who suggests the variation in definitions and countries studies is one of the reasons for the contradictory results in the studies that relate government size to economic growth (Bergh and Henrekson, 2011).

Livio di Matteo (Matteo, 2013c) suggested three important lessons:

1. The studies demonstrate that it is important to explicitly set out and adhere to consistent definitions of government size and economic growth.

2. The studies show that the analysis needs to be consistent in terms of the countries and economies being compared.

3. The studies show that even if there is a negative empirical relationship between government size and economic growth, the relationship may simply be due to reverse causality - that is, lower economic growth reduces resources for government and therefore leads to a smaller public sector.

These important lessons directs us to differentiate the efficiency measures used between public spending in developed and developing countries. All cross-country studies can only guide us in general terms, but no specific policies to implement. We should take for consideration top performing countries and conduct an in-depth study of their public budget policy. Here we can recommend emerging Asian countries, such as Singapore and South Korea, which were evaluated as top performing in both WGI government effectiveness index and Vito Tanzi PSE and PSP indexes for being the most efficient and effective in use of limited resources.

What is more, it is very important to mention the distinct variations inherent in countries. Another crosscountry study of 140 developing countries for 1996-2002 years in health and education spending found very interesting results and identified the main factors of efficiency variations in developing countries (Herrera and Pang, 2005a):

- The size of government expenditure

- A government budget composition variable

- Per-capita GDP

- Urbanization 
- Prevalance of AIDS

- Income distribution inequality

- Share of public sector in the provision of service

- External Aid

- Institutional Variables

"Results show that countries with higher expenditure levels register lower efficiency scores, as well as countries where the wage bill is a larger share of the government's budget. Similarly, countries with higher ratios of public to private financing of the service provision score lower efficiency, as do countries plagued by the HIV/AIDS epidemic and those with higher income inequality. Countries with higher aid-dependency ratios also tend to score lower in efficiency, probably due to the volatility of this type of funding that impedes medium term planning and budgeting".

Here, we will consider four variations most prevalent and of paramount importance in Central Asian countries: the size of government expenditure, a government budget composition variable, aid dependency and institutional variables.

First, if we compare overall level of public spending to GDP ratios of countries, we can see that this level in OECD developed countries may range from $30.2 \%$ of GDP in South Korea to $57.7 \%$ of GDP in Denmark as of 2011 (OECD, 2011). Public spending in developing countries range from $15 \%$ of GDP to $30 \%$ of GDP (Herrera and Pang, 2005b). This difference in levels of public spending of countries suggest that we cannot treat recommendations made for developed countries as definitive.

Second, the composition of government expenditures. "There is a strong evidence that as GDP rises the structure of public spending progressively shifts more heavily towards social outlays" (Palazzi, 1990). Developed countries' public spending is concentrated more on social expenditures. Actually all countries aim is economic growth that will ultimately bring human development. It suggests that social spending is significant component of overall public spending. The Paolo Palazzi introduced the concept of a sustainable level of development as the level of development characterized by an optimal ratio of GDP to social development. Corresponding to this theory developed countries really spend more on social facilities. In developing countries, it is found that agricultural spending, irrigation, education, and roads contributed strongly to growth, which means that governments should reduce their spending in unproductive sectors such as defense, that will help fight poverty (Fan and Rao, 2003). Therefore, developing countries should concentrate more on these types of public spending and work on improving efficiency and effectiveness of these expenditures.

Third, it is important to mention the international aid dependency of developing countries. Volatility of this type of funding hinders the sustainable fiscal policy planning and management thus negatively affect the efficiency and effectiveness of public spending.

Forth, institutions in Central Asian countries tend to be relatively weak than in developed countries. Consequently, we have higher corruption levels, which again hinders efficient and effective use of limited resources.

\subsection{Central Asian Countries' Public Spending}

Public spending in Central Asian countries range from in average terms in 1992-2000 it was $18.81 \%$, in 20012010 it was $25.02 \%$, and in $2011-2020$ it is $28.27 \%$. We can observe gradual growth of public expenditures, except for Turkmenistan and Uzbekistan. Uzbekistan public spending is far larger than other countries' before 2000 , and decreased from $41.55 \%$ to $33.88 \%$. Turkmenistan took the way of cutting public spending from $22.60 \%$ to $14.30 \%$. Other countries' spending is gradually growing except for Kazakhstan, which keeps the same level of $22.5 \%$. 


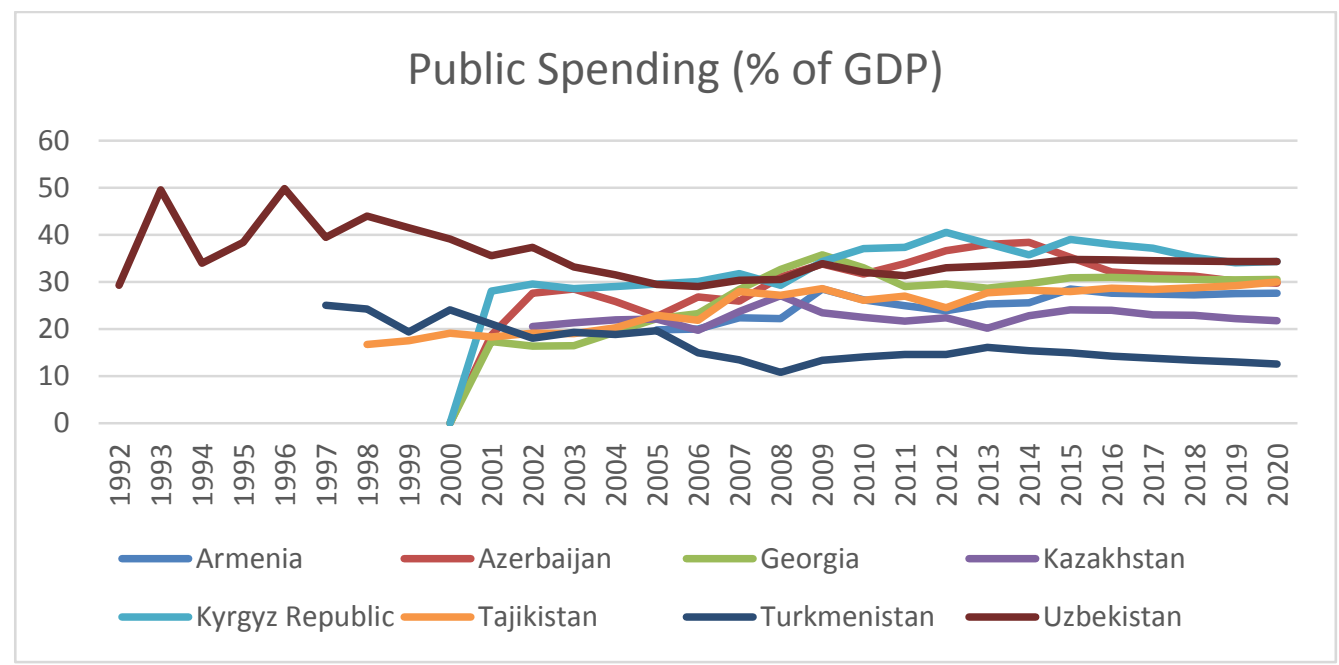

Figure 3. Public Spending of Central Asian Countries, IMF World Economic Outlook Database, April 2015.

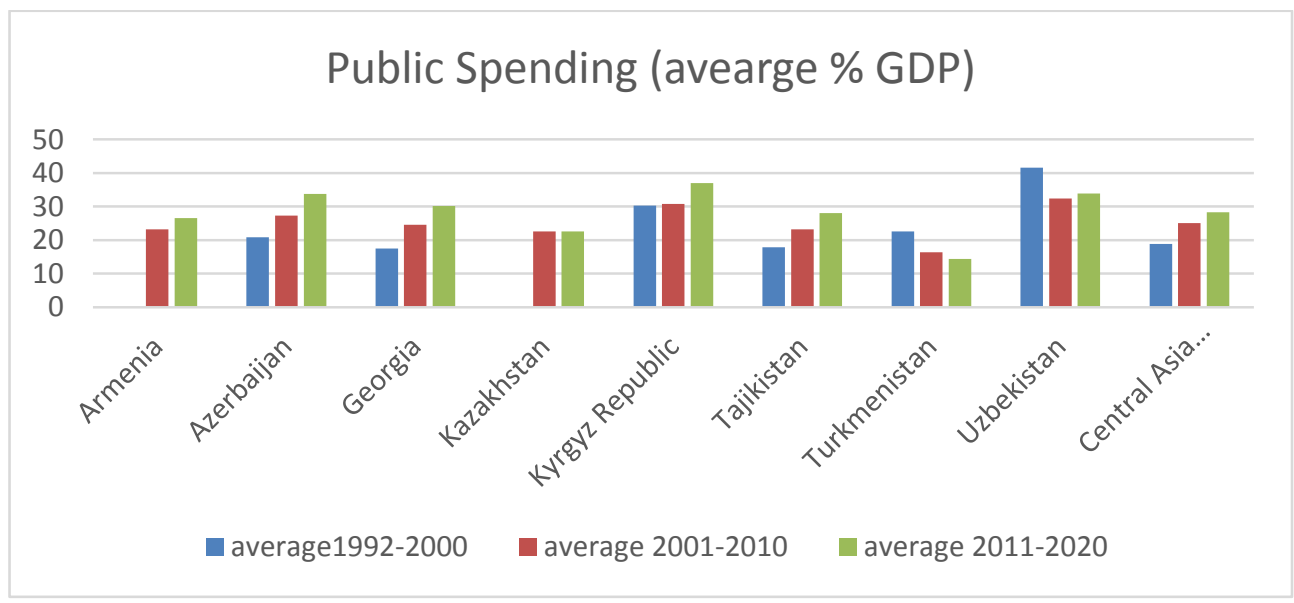

Figure 4. Public Spending of Central Asian Countries, IMF World Economic Outlook Database, April 2015.

The statistical data being collected are far from adequate. Therefore, we cannot apply the methods used for developed countries mentioned above. For available data, we can show correlation between variables of GDP growth and public spending in these countries. With basic correlation method used to determine whether or not GDP growth and growing public spending are correlated.

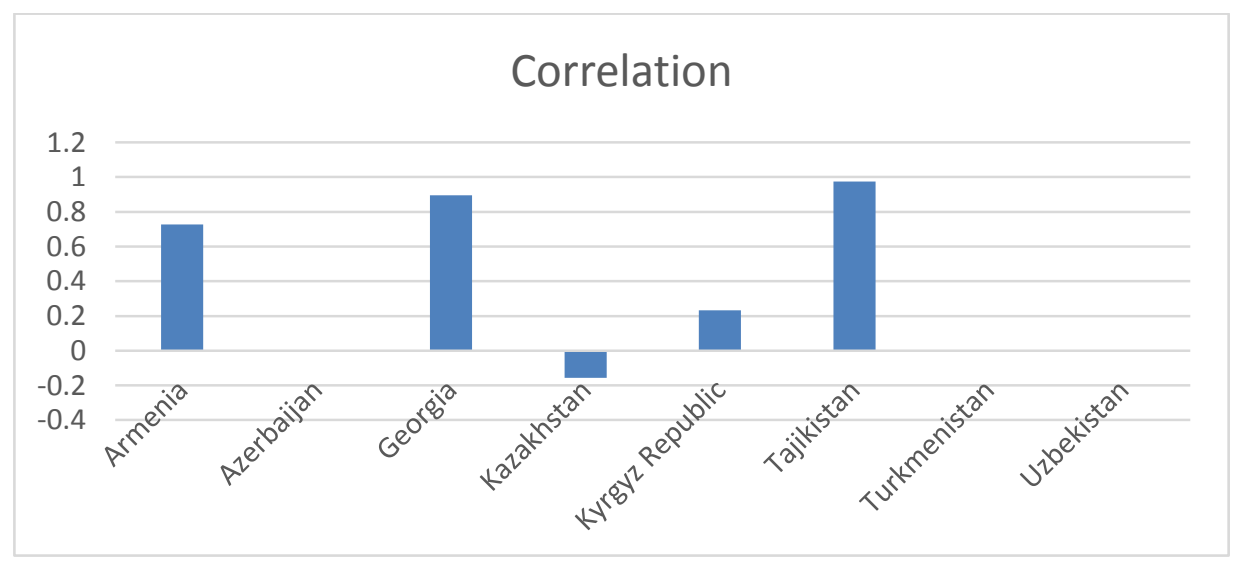

Figure 5. Correlation of GDP Growth and Change in Public Spending of Central Asian countries, WDI.

Relative high positive correlation is seen in Armenia (0.72), Georgia (0.89), and Tajikistan (0.97), Kyrgyz Republic (0.23), a negative correlation is in Azerbaijan (-0.01), and Kazakhstan (-0.15). For Turkmenistan and Uzbekistan data is not available.

If we look at composition of public spending in these countries, the dramatic change in composition of public spending in last decades in developed countries from government consumption, defence, direct spending on 
housing towards spending on social security, personal social services, health and education according Crawford and Johnson (Crawford and Johnson, 2011) leaves only two options. First is to increase the total public spending to adjust to growing demography. Many studies has shown a negative correlation between growing public spending and economic growth. Second is to implement reforms to reduce social spending. The second option is more viable and it points out the immediate and serious actions towards enhancing public sector performance through more productive use of public resources. Obviously, Central Asian countries way is not straightly following developed countries in changing composition of spending, but to take actions now, towards efficient use of public spending. There is no best fiscal policy, but certainly there is a way to be more productive. It is a way possible to have a small public sector but to be more efficient and rapidly prosper. Emerging Asian economies proved it and can guide us in how to achieve sustainable economic growth with limited resources in an efficient and effective way. Striclty dividing spending into productive and non-productive also will not guarantee economic growth. As S. Devarajan et al. (Devarajan et al, 1996) stated “... our empirical results suggest that expenditures which are normally considered productive could become unproductive if there is an excessive amount of them. In particular, capital expenditures - often thought to be the mainstay of development - may have been excessive in developing countries, rendering them unproductive at the margin”. Developing countries should avoid misallocating their limited resources in the recent conditions of lower commodity prices and tightening financial conditions.

\section{Concluding Remarks}

Today government's role changed towards reasonable intervention and careful use of limited resources. They search for the ways to enhance overall public sector performance. In this study, we analysed various methods used to evaluate the efficiency and effectiveness of public spending in developed and developing countries. Those methods suggested by Vito Tanzi et al., Livio di Matteo, Konstantinos Angelopoulos et al. are of significant econometric analysis methods and indicators evaluated are of high significance for efficiency measures. Overall, these authors suggested small-sized governments whose public spending is up to $30 \%$ of GDP are relatively more efficient. However, it does not speak for the current similar levels of Central Asian countries. In addition, there are contradictory results that enforces to differentiate efficiency measures used for developed and developing countries.

Due to the lack of data for Central Asian countries recently it is impossible to evaluate the comprehensive level of efficiency of public spending. The simple correlation method applied to eight countries of Central Asia shows diverse results, and it does not give any certain suggestions. Nevertheless, it is possible to suggest important points to consider. First of all, any developing country should not straightly follow any developed country and decrease or increase its public spending. The second thing is to think over the composition of public expenditures. At last, pay attention to factors of variations in efficiency: the size of government expenditure, a government budget composition variables, per-capita GDP, urbanization, prevalence of AIDS, income distribution inequality, share of public sector in the provision of service, external aid, and institutional variables. The author concludes that Central Asian countries are less efficient than developed countries because of four distinct problems: the size of government expenditure, a government budget composition, aid dependency, and weak institutions.

\section{References}

- Rothstein, 2011. "The Quality of Government: Corruption, Social Trust and Inequality in a Comparative Perspective", Chicago: University of Chicago Press.

- Rajkumar and Swaroop, 2002. “Public Spending and Outcomes: Does Governance Matter?”, Policy Research Working Paper, World Bank, http://dx.doi.org/10.1596/1813-9450-2840

- Solow, 1956. “A Contribution to the Theory of Economic Growth”, The Quarterly Journal of Economics, 70 (1), pp. 65-94.

- Lucas, 1988. "On the Mechanics of Economic Development”, Journal of Monetary Economics, 22, pp. 342.

- Hogendorn, 1996. Economic Development. Harper Collins College Publishers, Inc., New York, p56-64.

- Holzer, 1992. Public Finance. Soros Fund, Bishkek, pp. 323-350.

- Tanzi, 2005. "The Economic Role of the State in 21st Century”, Cato Journal, 25 (3), pp. 617-638.

- Schick, 2005. "Sustainable Budget Policy: Concepts and Approaches", OECD Journal on Budgeting, 5 (1), pp. 107-126.

- United Nations, 2002. "Finance for Sustainable Development: Testing New Policy Approaches: Proceedings of the Fifth Expert Group Meeting on Finance for Sustainable Development”, Nairobi, Kenya, 1-4 December 1999. 
- Rothstein and Teorell, 2012. "Defining and measuring quality of government", http://iisdb.stanford.edu/docs/623/Rothstein\%26Teorell2012.pdf

- Worldwide Governance Indicators, 2013. http://info.worldbank.org/governance/wgi/index.aspx\#home

- Worthington and Dollery, 2000. “An Empirical Survey of Frontier Efficiency Measurement Techniques in Local Government”, Local Government Studies, 26 (2), pp. 23-52.

- Ulrike Mandl et al., 2008. The Effectiveness and Efficiency of Public Spending, Economic Papers 301.

- Chu et al., 1995. "Unproductive Public Expenditures, A Pragmatic Approach To Policy Analysis", IMF Pamphlet Series No. 48.

- Baumol and Bradford, 1970. "Optimal Departures from Marginal Cost Pricing", The American Economic Review, 60, pp. 265-283.

- Barro, 1990. "Government Spending in a Simple Model of Endogeneous Growth", The Journal of Political Economy, 98 (S5), pp. 103-125.

- Matteo, 2013. Measuring Government in the Twenty-first Century: An International Overview of the Size and Efficiency of Public Spending, Fraser Institure, Canada.

- Tanzi, 2011. Government versus Markets: The Changing Economic Role of the State, Cambridge University Press, New York.

- Tanzi, 1997. "The Changing Role of Fiscal Policy in Fund Policy Advice", https://www.imf.org/external/np/apd/asia/TANZI.HTM

- Tanzi et al., 2010. "Public sector efficiency: evidence for new EU member states and emerging markets", Applied Economics, 42: 2147-2164.

- Baumol, 1970. "On the Discount Rate of Public Projects”, in Public Expenditures and Policy Analysis, Chicago: Markham, p. 274.

- Slemrod, 1995. "What Do Cross-Country Studies Teach about Government Involvement, Prosperity, and Economic Growth?”, William Easterly, Brookings Papers on Economic Activity.

- Angelopoulos et al., 2008. "Does public sector efficiency matter? Revisiting the relation between fiscal size and economic growth in a world sample", Athens University of Economics \& Business, University of Glasgow, and CESifo.

- Nijkamp, P. and J. Poot, 2004. "Meta-Analysis of the Effect of Fiscal Policies on Long-Run Growth", European Journal of Political Economy, 20, pp. 91-124.

- Lee and Whithford, 2009. "Government Effectiveness in Comparative Perspective", Journal of Comparative Policy Analysis, 11(2), pp. 249-281.

- Bergh and Henrekson, 2011. "Government Size and Growth: A Survey and Interpretation of the Evidence", IFN Working Paper No. 858

- Herrera and Pang, 2005. "Efficiency of Public Spending in Developing Countries: An Efficiency Frontier Approach 1", World Bank Policy Research Working Paper 3645.

- OECD, 2011. General government spending, https://data.oecd.org/gga/general-government-spending.htm

- Palazzi, 1990, “The Structure of Public Spending and Development”, Dipartimento di Scienze Economiche Universita' "la Sapienza", Roma.

- Fan and Rao, 2003. "Public Spending in Developing Countries", Environment and Production Technology Division International Food Policy Research Institute, N.W. Washington, D.C.

- IMF, 2015. World Economic Outlook Database, https://www.imf.org/external/pubs/ft/weo/2015/01/weodata/index.aspx

- Crawford and Johnson, 2011. "The changing composition of public spending”, IFS Briefing Note 119, Institute for Fiscal Studies.

- Devarajan et al., 1996. "The Composition of Public Expenditure and Economic Growth ”, Journal of Monetary Economics, 37, pp. 313-344. 